\title{
Nocturnal saturation and respiratory muscle function in patients with chronic obstructive pulmonary disease
}

\author{
Y F Heijdra, P N R Dekhuijzen, C L A van Herwaarden, H Th M Folgering
}

\begin{abstract}
Background - Nocturnal desaturations, mainly caused by hypoventilation, occur frequently in patients with chronic obstructive pulmonary disease (COPD). Daytime arterial oxygen and carbon dioxide tensions $\left(\mathrm{PaO}_{2}\right.$ and $\left.\mathrm{PaCO}_{2}\right)$ appear to predict which patients will desaturate at night. It is unknown if respiratory muscle strength, which may be decreased in these patients, plays an additional part.

Methods - Polysomnography, maximal respiratory pressures, lung function, and arterial blood gas tensions were measured in 34 patients with COPD (mean (SD) forced expiratory volume in one second (FEV $)_{1} 41.7$ (19.9)\% pred).

Results - Significant correlations were found between the mean nocturnal arterial oxygen saturation and maximal inspiratory mouth pressure $(r=0.65)$, maximal inspiratory transdiaphragmatic pressure $(r=0.53), \mathrm{FEV}_{1}(r=0.61)$, transfer coefficient (KCO) $(r=0.38)$, arterial oxygen saturation $\left(\mathrm{SaO}_{2}\right)(r=0 \cdot 75)$, and $\mathrm{PaCO}_{2}(r=-0 \cdot 44)$. Multiple regression analysis showed that $75 \%$ of the variance in nocturnal $\mathrm{SaO}_{2}$ was explained by a combination of $\mathrm{SaO}_{2}(70 \%)$ and $\mathrm{FEV}_{1}(5 \%)$.

Conclusion - Inspiratory muscle strength and nocturnal saturation data are correlated, but daytime $\mathrm{SaO}_{2}$ and $\mathrm{FEV}_{1}$ remain the most important predictors of nocturnal saturation.

(Thorax 1995;50:610-612)
\end{abstract}

Keywords: nocturnal saturation, respiratory muscle strength, chronic obstructive pulmonary disease.

\footnotetext{
Department of Pulmonary Diseases, University of Nijmegen, Medical Centre Dekkerswald, PO Box 9001, $6560 \mathrm{~GB}$

Groesbeek, The Netherlands Y F Heijdra P N R Dekhuijzen C L A van Herwaarden $\mathrm{H}$ Th $M$ Folgering

Reprint requests to: Dr Y F Heijdra.

Received 11 July 1994 Returned to authors 21 September 1994 Revised version received 17 November 1994 Accepted for publication 7 Accepted for put
}

study was therefore to evaluate the relation between inspiratory muscle strength and nocturnal saturation in 34 stable patients with COPD. In addition, the contribution of inspiratory muscle strength to the prediction of nocturnal saturation was investigated.

\section{Methods}

Thirty four patients with stable COPD $^{6}(30$ men, mean (SD) forced expiratory volume in one second $\left(\mathrm{FEV}_{1}\right) 41 \cdot 7$ (19.9)\% pred) were included in the study which was approved by the hospital medical ethics committee. Patients with an obstructive sleep apnoea syndrome or an overlap syndrome were excluded.

Polysomnography was performed including arterial oxygen saturation, heart rate, end tidal $\mathrm{PCO}_{2}\left(\mathrm{PETCO}_{2}\right)$, thoracic movements, and electro-oculography (EOG). Oxygen saturation $\left(\mathrm{SaO}_{2}\right)$ and heart rate were measured in a real time format by a pulse oximeter. A desaturation was defined by a combination of the definition of Block et $a l^{7}$ and Fletcher et $a l^{8}$ as a decrease by more than $4 \%$ in oxygenation from the baseline saturation when awake for a period of five minutes or more. PETCO $_{2}$ was measured with a sampling capnograph by introducing a catheter into the nasopharyngeal cavity. The baseline awake and asleep $\mathrm{SaO}_{2}$ and $\mathrm{PETCO}_{2}$ were defined as the mean $\mathrm{SaO}_{2}$ and $\mathrm{PETCO}_{2}$ during the first 15 minutes of the record and while asleep, respectively. Since $\mathrm{PeTCO}_{2}$ is not representative of arterial $\mathrm{PCO}_{2}$, increases in $\mathrm{PETCO}_{2}$ signals were only used qualitatively as indicators of hypoventilation ${ }^{9}$ in combination with saturation and thoracic movement signals. Thoracic movements were analysed by respiratory inductive plethysmography. An EOG was measured with surface electrodes and used for visual scoring of wakefulness, non-REM and REM sleep, in combination with the other signals. ${ }^{10}$ When rapid eye movements were present and desaturations occurred in the absence of gross body movements, it was even more likely that REM sleep was present. ${ }^{11}$

Static maximal inspiratory and expiratory mouth pressures (PImax, Pemax), as well as static maximal inspiratory transdiaphragmatic pressure (PDI), were measured as described previously. ${ }^{12}$ The inspiratory manoeuvre at residual volume (RV) and the expiratory manoeuvre at total lung capacity (TLC) were repeated until three reproducible measurements had been made with a maximal variability of $10 \%$. The highest values were used for analysis. The inspiratory pressures were 
Table 1 Mean (SD) nocturnal measurements

\begin{tabular}{lr}
\hline Baseline $\mathrm{SaO}_{2}$ awake (\%) & $93 \cdot 5(2 \cdot 5)$ \\
Mean nocturnal $\mathrm{SaO}_{2}(\%)$ & $90 \cdot 6(4 \cdot 5)$ \\
$\%$ time desaturated (\%) & $19 \cdot 1(27 \cdot 8)$ \\
Lowest nocturnal SaO $(\%)$ & $83 \cdot 3(12 \cdot 2)$ \\
Baseline PETCO $_{2}$ awake (kPa) & $5 \cdot 0(0 \cdot 7)$ \\
PETCO $_{2}$ asleep (kPa) & $5 \cdot 5(0 \cdot 9)$ \\
Time in bed (min) & $454(48)$ \\
Time in non-REM (min) & $249(69)$ \\
Time in REM (min) & $49(21)$ \\
\hline
\end{tabular}

$\mathrm{SaO}_{2}=$ arterial oxygen saturation; $\mathrm{PETCO}_{2}=$ end tidal carbon dioxide tension; REM = rapid eye movement sleep.

expressed as absolute values. Predicted values for respiratory muscle strength were derived from Wilson et al. ${ }^{13}$

\section{DATA ANALYSIS}

Data are presented as means (SD). Spearman correlation tests were performed, $p$ values of $<0.05$ being considered significant. Stepwise multiple regression analysis was used to assess which parameters were independent predictors of the nocturnal and daytime saturation. The significance level for retention in the model was $0 \cdot 05$.

\section{Results}

The mean age of the patients was $61 \cdot 4(6 \cdot 4)$ years. They had a wide variation of airways

Table 2 Spearman's correlation coefficients between daytime characteristics and nocturnal saturation data

\begin{tabular}{lccc}
\hline Daytime parameters & $\begin{array}{l}\text { Mean nocturnal } \\
\mathrm{SaO}_{2}(\%)\end{array}$ & $\begin{array}{l}\text { Lowest nocturnal } \\
\mathrm{SaO}_{2}(\%)\end{array}$ & $\begin{array}{l}\text { \% time desaturated } \\
(\%)\end{array}$ \\
\hline PImax (kPa) & $0.65^{* * *}$ & $0.60^{* * *}$ & $-0.64^{* * * *}$ \\
$\mathrm{PDI}(\mathrm{kPa})$ & $0.53^{* *}$ & $0.47^{* *}$ & $-0.60^{* * *}$ \\
$\mathrm{SaO}_{2}(\%)$ & $0.75^{* * *}$ & $0.64^{* * *}$ & $-0.67^{* * *}$ \\
$\mathrm{PacO}_{2}(\mathrm{kPa})$ & $-0.44^{* *}$ & $-0.45^{* *}$ & $0.47^{* *}$ \\
$\mathrm{FEV}$ & $0.61^{* * *}$ & $0.53^{* *}$ & $-0.58^{* * *}$ \\
$\mathrm{KcO}(\%$ pred) & $0.39^{*}$ & 0.36 & $-0.34^{*}$ \\
\hline
\end{tabular}

PImax = static maximal inspiratory mouth pressure; $\mathrm{PDI}=$ static maximal inspiratory transdiaphragmatic pressure; $\mathrm{SaO}_{2}=$ arterial oxygen saturation; $\mathrm{PaCO}_{2}=$ arterial carbon dioxide tension; diaphragmatic pressure; $\mathrm{SaO}_{2}=$ arterial oxygen saturation; $\mathrm{PaCO}_{2}=$ arterial carbon dioxide tension;
$\mathrm{FEV}_{1}=$ forced expiratory volume in one second; $\mathrm{KCO}=$ carbon monoxide transfer coefficient. $\mathrm{FEV}_{1}=$ forced expiratory volume in
${ }^{\mathrm{p}}<0.05 ;{ }^{* *} \mathrm{p}<0.01 ;{ }^{* * *} \mathrm{p}<0.001$

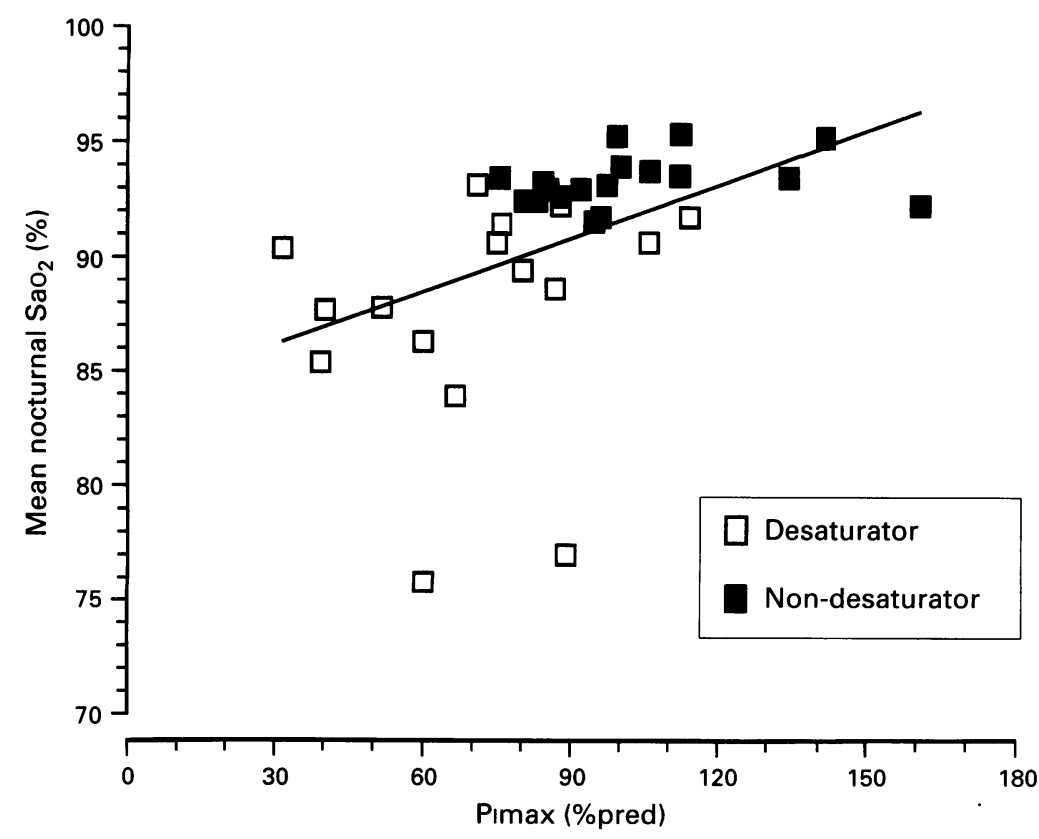

Relation between maximal inspiratory mouth pressure (PImax) (\% pred) and mean nocturnal arterial oxygen saturation (\%); $r=0.63, p<0.001$. obstruction $\left(\mathrm{FEV}_{1} \quad 0 \cdot 6-3 \cdot 21\right.$, mean $41 \cdot 7$ $(19 \cdot 9) \%$ pred). They were hyperinflated (functional residual capacity (FRC) $(127 \cdot 8(31 \cdot 2) \%$ pred)) and had a low gas transfer coefficient capacity (KCO) of $57.5(28.5) \%$ pred. Four patients were hypoxaemic $\left(\mathrm{PaO}_{2}<8.0 \mathrm{kPa}\right)$ and two patients were hypoxaemic and hypercapnic $\left(\mathrm{PaCO}_{2}>6.5 \mathrm{kPa}\right)$. The mean $\mathrm{PaO}_{2}$ and $\mathrm{PaCO}_{2}$ were $9.3(1.3) \mathrm{kPa}$ and $5.7(0.7) \mathrm{kPa}$, respectively.

All patients had at least one period of REM sleep and, in the whole group, $10 \cdot 8(4 \cdot 6) \%$ of the recording time was spent in REM sleep. Of the 34 patients 16 developed episodes with desaturations during the night. In these 16 patients the mean desaturation time and the mean REM sleep time were $40 \cdot 6(27 \cdot 7) \%$ and $11.6(4.0) \%$ of the total recording time, respectively. In these patients $64 \cdot 0(35 \cdot 2) \%$ of the total REM sleep time was spent desaturated, which represents $18 \cdot 2 \%$ of the total desaturation time. The polysomnographic data are shown in table 1.

PImax, PDI, and Pemax were $6.9(2.3) \mathrm{kPa}$ (87.5 (27)\% pred), 9.7 (3.6) kPa, and 8.9 (3.0) $\mathrm{kPa}(73 \cdot 1(22 \cdot 2) \%$ pred), respectively. In four patients PDI was not measured because of inability to swallow the oesophageal catheter. The correlation coefficients between nocturnal saturation data and daytime characteristics are presented in table 2 . The highest correlation coefficient was found between daytime and nocturnal saturation.

The correlation between PImax ( $\%$ pred) and mean nocturnal arterial oxygen saturation $\left(\mathrm{SaO}_{2}\right)(\%)$ is shown in the figure. There was a large overlap between patients who did and did not desaturate.

Stepwise multiple regression analysis was used to evaluate the contribution of various parameters in the prediction of the mean nocturnal saturation. The input variables were the daytime parameters shown in table 2 . Of the variance in mean nocturnal $\mathrm{SaO}_{2}, 75 \%$ was explained by a combination of daytime $\mathrm{SaO}_{2}$ $(70 \%)$ and $\mathrm{FEV}_{1}(5 \%)$. A similar analysis was performed to predict daytime $\mathrm{SaO}_{2}$ with the variables PImax $(\mathrm{kPa})$, PDI $(\mathrm{kPa}), \mathrm{FEV}_{1}(\%$ pred), FRC (\% pred), and Kco ( $\%$ pred). PDI was the only predictive variable $\left(r^{2}=0 \cdot 33\right)$.

\section{Discussion}

This study shows that maximal inspiratory muscle strength and nocturnal saturation data are significantly correlated in patients with COPD. However, daytime $\mathrm{SaO}_{2}$ and $\mathrm{FEV}_{1}$ remain the most important predictors of nocturnal saturation.

An important case of hypoventilation during REM sleep is diminished respiratory activity of the intercostal and accessory muscles ${ }^{14}$ which increases the workload of the diaphragm. However, strength and endurance of the diaphragm in patients with COPD may be affected by their unfavourable position on the length-tension curve due to hyperinflation. ${ }^{3}$ It was therefore hypothesised that a relation may exist between nocturnal arterial oxygen saturation and maximal inspiratory muscle strength, and a sig- 
nificant correlation was, indeed, shown between these two parameters (figure). However, if patients were divided into those who desaturated and those who did not, a considerable overlap was seen between the two groups. PImax and PDI appear to have a low predictive value and this was confirmed by multiple regression analysis. Daytime $\mathrm{SaO}_{2}$ and $\mathrm{FEV}_{1}$ were the only independent predictors and explained $75 \%$ of the variance in the mean nocturnal saturation. However, PDI was the only predictive variable for daytime $\mathrm{SaO}_{2}$ so an indirect effect on nocturnal saturation via daytime $\mathrm{SaO}_{2}$ is also possible. The finding that $\mathrm{FEV}_{1}$ was one of the independent predictors, in contrast to other studies, ${ }^{1516}$ may be explained by the wide range of $\mathrm{FEV}_{1}$ values $(0 \cdot 6-3 \cdot 21)$ in our patients.

The significance of daytime $\mathrm{SaO}_{2}$ in predicting the nocturnal saturation has been described previously. Bradley et $a l^{4}$ showed that daytime $\mathrm{SaO}_{2}$ and $\mathrm{PaCO}_{2}$ accounted for $68 \%$ of the variability of the nocturnal saturation in patients with COPD. In another study a high correlation was found between daytime and nocturnal $\mathrm{SaO}_{2}$ in 97 patients with COPD. ${ }^{5}$

The definition of a desaturation as a decrease of more than $4 \%$ in $\mathrm{SaO}_{2}$ lasting at least five minutes was derived from the study of Block $e t a l^{7}$ combined with that of Fletcher et $a l^{8}$ who defined a nocturnal desaturation as a fall below $90 \%$ lasting at least five minutes or more. This latter study described desaturations in patients with COPD in whom, in general, a serious desaturation lasted longer than five minutes, in contrast to patients with obstructive sleep apnoea in whom clinically important desaturations can last as little as 10 seconds. In addition, desaturations caused by movement usually last less than five minutes.

The patients in this study spent a long time awake. This is probably due to the long recording time, defined as the total time patients spent in bed attached to the polysomnographic apparatus, because the time spent in REM and non-REM sleep was comparable to other sleep studies performed in patients with COPD. ${ }^{58111617}$ When the total recording time and the time patients were awake in our study were compared with the study of Gothe $e t a l^{17}$ similar results were found. The total recording time and the time spent awake were 454 (48) minutes versus 449 (80) minutes, and 156 (58) minutes versus 188 (85) minutes in our study and that of Gothe et al, respectively.

Little is known about the impact of an experimental situation on sleep stage variability, $\mathrm{SaO}_{2}$, and breathing pattern in patients with
COPD. Two studies have shown that mean and lowest $\mathrm{SaO}_{2}$ and breathing pattern did not differ during two nights. ${ }^{1718}$ Based on these data we presume that the outcome of the present study was not influenced by studying patients for only one night.

In conclusion, this study shows significant correlations between maximal inspiratory muscle strength and nocturnal saturation data in patients with COPD. However, $75 \%$ of the variability in mean nocturnal $\mathrm{SaO}_{2}$ was explained by daytime $\mathrm{SaO}_{2}$ and $\mathrm{FEV}_{1}$.

This study was supported by a grant from the Dutch Asthma Foundation.

1 Hudgel DW, Martin RJ, Capehart M, Johnson B, Hill P. Contribution of hypoventilation to sleep oxygen desaturation in chronic obstructive pulmonary disease. $\mathcal{f}$ Appl Physiol 1983;55:669-77.

2 Johnson MW, Remmers JE. Accessory muscle activity during sleep in chronic obstructive pulmonary disease. $\mathcal{f} A p p l$ Physiol 1984;57:1011-7.

3 Rochester DF, Braun NMT. Determinants of maximal inspiratory pressure in chronic obstructive pulmonary disease. Am Rev Respir Dis 1985;132:42-7.

4 Bradley TD, Mateike J, Li D, Avendano M, Goldstein RS. Daytime hypercapnia in the development of nocturnal hypoxemia in COPD. Chest 1990;97:308-12.

5 Connaughton JJ, Catterall JR, Elton RA, Stradling JR, Douglas NJ. Do sleep studies contribute to the management of patients with severe chronic obstructive pulmonary disease? Am Rev Respir Dis 1988;138:341-4.

6 American Thoracic Society. Standards for the diagnosis and care of patients with chronic obstructive pulmonary disease (COPD) and asthma. Am Rev Respir Dis 1987;136:225-44.

7 Block AJ, Boysen PG, Wynne JW, Hunt LA. Sleep apnea, hypopnea and oxygen saturation in normal subjects. $N$ Engl f Med 1979;10:513-7.

8 Fletcher EC, Scott D, Qian W, Luckett RA, Miller CC, Goodnight-White S. Evolution of nocturnal oxyhemoglobin desaturation in patients with chronic obstructive pulmonary disease and a daytime $\mathrm{PaO}_{2}$ above $60 \mathrm{~mm} \mathrm{Hg}$. Am Rev Respir Dis 1991;144:401-5

9 Vos PJE, Folgering HThM, van Herwaarden CLA. Nocturnal end-tidal $\mathrm{PCO}_{2}$ to detect apnoeas and hypopnoeas in sleep-disordered breathing. Physiol Meas 1993;14:433-9.

10 Stradling JR. Sleep studies for sleep-related breathing disorders. $\mathcal{F}$ Sleep Res 1992;1:265-73.

11 Gould GA, Gugger M, Molloy J, Tsara V, Shapiro CM, Douglas NJ. Breathing pattern and eye movement density during REM sleep in humans. Am Rev Respir Dis 1988; 138:874-7.

12 Heijdra YF, Dekhuijzen PNR, van Herwaarden CLA, Folgering HThM. Effects of body position, hyperinflation, and blood gas tensions on maximal respiratory pressures in patients with chronic obstructive pulmonary disease. in patients with chronic

13 Wilson SH, Cooke NT, Edwards RHT, Spiro SG. Predicted normal values for maximal respiratory pressures in caucasian adults and children. Thorax 1984;39:535-8.

14 Tabachnik E, Muller NL, Bryan AC, Levison H. Changes in ventilation and chest wall mechanics during sleep in normal adolescents. $¥$ Appl Physiol 1981;51:557-64.

15 Fletcher EC, Miller J, Divine GW, Fletcher JG, Miller T. Nocturnal oxyhemoglobine desaturation in COPD patients with arterial oxygen tensions above $60 \mathrm{~mm} \mathrm{Hg}$. Chest 1987;92:604-8.

16 Tatsumi K, Kimura H, Kunitomo F, Kuriyama T, Watanabe $S$, Honda Y. Sleep arterial oxygen desaturation and chemical control of breathing during wakefulness in COPD. Chest 1986;90:68-73.

17 Gothe B, Hanekamp LM, Cherniak NS. Reproducibility of ventilatory measurements during sleep on different nights in patients with chronic obstructive pulmonary disease. $f$ Lab Clin Med 1987;109:608-16.

18 Stradling JR, Lane DJ. Nocturnal hypoxaemia in chronic obstructive pulmonary disease. Clin Sci 1982;64:213-22. 